\title{
Retention Enhancement in Low Power NOR Flash Array with High- $\kappa-B a s e d$ Charge-Trapping Memory by Utilizing High Permittivity and High Bandgap of Aluminum Oxide
}

\author{
Young Suh Song ${ }^{1,2}$ and Byung-Gook Park ${ }^{1, *}$ a \\ 1 Department of Electrical and Computer Engineering, Seoul National University, Seoul 08826, Korea; \\ sys1413@snu.ac.kr \\ 2 Department of Computer Science, Korea Military Academy, Seoul 01805, Korea \\ * Correspondence: bgpark@snu.ac.kr
}

\section{check for} updates

Citation: Song, Y.S.; Park, B.-G. Retention Enhancement in Low Power NOR Flash Array with High- $\mathrm{k}-$ Based Charge-Trapping Memory by Utilizing High Permittivity and High Bandgap of Aluminum Oxide. Micromachines 2021, 12, 328. https://doi.org/ $10.3390 / \mathrm{mi1} 2030328$

Academic Editors: Cristian Zambelli and Rino Micheloni

Received: 15 February 2021

Accepted: 15 March 2021

Published: 19 March 2021

Publisher's Note: MDPI stays neutral with regard to jurisdictional claims in published maps and institutional affiliations.

Copyright: (c) 2021 by the authors. Licensee MDPI, Basel, Switzerland. This article is an open access article distributed under the terms and conditions of the Creative Commons Attribution (CC BY) license (https:/ / creativecommons.org/licenses/by/ $4.0 /)$.

\begin{abstract}
For improving retention characteristics in the NOR flash array, aluminum oxide $\left(\mathrm{Al}_{2} \mathrm{O}_{3}\right.$, alumina) is utilized and incorporated as a tunneling layer. The proposed tunneling layers consist of $\mathrm{SiO}_{2} / \mathrm{Al}_{2} \mathrm{O}_{3} / \mathrm{SiO}_{2}$, which take advantage of higher permittivity and higher bandgap of $\mathrm{Al}_{2} \mathrm{O}_{3}$ compared to $\mathrm{SiO}_{2}$ and silicon nitride $\left(\mathrm{Si}_{3} \mathrm{~N}_{4}\right)$. By adopting the proposed tunneling layers in the NOR flash array, the threshold voltage window after 10 years from programming and erasing $(\mathrm{P} / \mathrm{E})$ was improved from $0.57 \mathrm{~V}$ to $4.57 \mathrm{~V}$. In order to validate our proposed device structure, it is compared to another stacked-engineered structure with $\mathrm{SiO}_{2} / \mathrm{Si}_{3} \mathrm{~N}_{4} / \mathrm{SiO}_{2}$ tunneling layers through technology computer-aided design (TCAD) simulation. In addition, to verify that our proposed structure is suitable for NOR flash array, disturbance issues are also carefully investigated. As a result, it has been demonstrated that the proposed structure can be successfully applied in NOR flash memory with significant retention improvement. Consequently, the possibility of utilizing $\mathrm{HfO}_{2}$ as a charge-trapping layer in NOR flash application is opened.
\end{abstract}

Keywords: retention characteristic; high-к; nonvolatile charge-trapping memory; stack engineering; NOR flash memory; aluminum oxide

\section{Introduction}

With the advent of the Fifth Generation Mobile Networks (5G) era, the demand for big data has increased rapidly in recent years [1-3], and the need for memory devices enabling more data storage has consistently increased [4,5]. In order to satisfy these demands, novel memory devices utilizing new materials such as aluminum oxide $\left(\mathrm{Al}_{2} \mathrm{O}_{3}\right.$, alumina), hafnium oxide $\left(\mathrm{HfO}_{2}\right)$, zirconium dioxide $\left(\mathrm{ZrO}_{2}\right)$, stacked $\mathrm{HfO}_{2} / \mathrm{Al}_{2} \mathrm{O}_{3}$, and nano-laminated forms $\left(\mathrm{HfAlO}_{\mathrm{x}}\right)$ have been widely proposed and studied [6-8].

Among them, hafnium oxide $\left(\mathrm{HfO}_{2}\right)$ has a tremendous advantage as a charge-trapping layer (CTL) material, since its charge trap density is four times higher than that of the conventional charge-trapping layer (CTL), silicon nitride $\left(\mathrm{Si}_{3} \mathrm{~N}_{4}\right)$ [9,10]. This enriched CTL density of $\mathrm{HfO}_{2}$ can enable a wider threshold voltage $\left(V_{\mathrm{TH}}\right)$ window and improved memory margin [11,12]. Furthermore, permittivity of $\mathrm{HfO}_{2}$ is much higher than that of $\mathrm{Si}_{3} \mathrm{~N}_{4}$, which enables significant reduction in equivalent oxide thickness (EOT) of the gate stack [13-17]. This enables low program voltage $\left(V_{\mathrm{PGM}}\right)$, low erase voltage $\left(V_{\mathrm{ERS}}\right)$, fast program/erase (P/E) speed, fast switching speed, and low power consumption.

From these various advantages of higher charge trap density and the possibility of reducing EOT, $\mathrm{HfO}_{2}$-based charge-trapping memories (CTM) have been widely studied for fast, high-capacity nonvolatile memory devices [18-21]. However, despite these advantages, $\mathrm{HfO}_{2}$ has encountered many limitations in commercialization due to retention problems that come from its numerous shallow traps [22-25]. Therefore, this issue needs to be solved for realizing practical high- $k-$ based charge-trapping memory (HCTM). 
In order to solve these retention issues, the use of $\mathrm{Al}_{2} \mathrm{O}_{3}$ as a CTL in a metal $/ \mathrm{Al}_{2} \mathrm{O}_{3} / \mathrm{SiO}_{2} / \mathrm{Si}$ (MAOS) structure has been proposed, but it also suffers from retention problems due to vertical leakage current $[26,27]$. Another previous solution of simply increasing the thickness of tunneling oxide layers has been proposed to mitigate this retention problem; however, this approach concomitantly results in the degradation in P/E speed and subthreshold swing (SS) due to an increase in EOT of the gate stack [28-31]. Furthermore, this approach inevitably increases $V_{\mathrm{PGM}}, V_{\mathrm{ERS}}$, and power consumption. Therefore, a new approach is needed to solve these issues.

In this framework, the aim of this paper is to 1) improve retention characteristics of $\mathrm{HfO}_{2}$-based CTM by using tunneling oxide layers of $\mathrm{SiO}_{2} / \mathrm{Al}_{2} \mathrm{O}_{3} / \mathrm{SiO}_{2}$ and 2) validate that our proposed structure can be well applied in the NOR flash array, which has been broadly studied for unsupervised learning [32,33]. For validating retention improvement in the proposed memory device structure, it is also compared with the other bandgap engineering (BE) tunneling oxide layers with $\mathrm{SiO}_{2} / \mathrm{Si}_{3} \mathrm{~N}_{4} / \mathrm{SiO}_{2}$ [34-36].

Consequently, it has been demonstrated that the retention characteristics can be significantly improved in a high- $\kappa-$ based NOR flash memory device by utilizing the advanced tunneling layers with $\mathrm{SiO}_{2} / \mathrm{Al}_{2} \mathrm{O}_{3} / \mathrm{SiO}_{2}$ on the tunnel field effect transistor (TFET) structure, which has been broadly studied for low power application [37-44]. From an array perspective, it has been demonstrated that the proposed memory device structure is also able to inhibit the programming in unselected cells by bottom gate effect. Namely, we have designed the memory device structure which is free from disturbance issues in the NOR flash array with enhanced retention characteristics.

This paper is organized as follows. First, the basic transfer characteristics are analyzed after calibration. Second, performance of inhibition in the NOR flash array is demonstrated. Then, improvement of the retention characteristics is carefully analyzed with various perspectives. Finally, the expected advantage of applying our proposed memory device structure in the NOR flash array is discussed.

\section{Device Structure and Model Physics}

\subsection{Structure of the Proposed Memory Device}

In previous research, the advanced bandgap-engineered $\mathrm{TaN} / \mathrm{Al}_{2} \mathrm{O}_{3} / \mathrm{HfO}_{2} / \mathrm{SiO}_{2} / \mathrm{Si}$ (BE-TAHOS) structure has been investigated for a faster erasing speed and larger memory window by incorporating $\mathrm{Si}_{3} \mathrm{~N}_{4}$ at the tunneling oxide layer [37-44]. By utilizing this BE-TAHOS structure [34-36] and applying $\mathrm{Al}_{2} \mathrm{O}_{3}$ at the tunneling layer, the advanced structure of TaN $/ \mathrm{Al}_{2} \mathrm{O}_{3} / \mathrm{HfO}_{2} / \mathrm{SiO}_{2} / \mathrm{Al}_{2} \mathrm{O}_{3} / \mathrm{SiO}_{2} / \mathrm{Si}$ (TAHOAOS) is designed for NOR flash memory.

Cross-sectional views of conventional TaN $/ \mathrm{Al}_{2} \mathrm{O}_{3} / \mathrm{HfO}_{2} / \mathrm{SiO}_{2} / \mathrm{Si}$ (TAHOS), BE-TAHOS, and that of the proposed TAHOAOS structure are schematically shown in Figure 1. In order to compare the proposed TAHOAOS structure with not only conventional TAHOS but also the BE-TAHOS structure, BE-TAHOS is also designed with $\mathrm{SiO}_{2} / \mathrm{Si}_{3} \mathrm{~N}_{4} / \mathrm{SiO}_{2}$ tunneling oxide layers [34-36]. The devices designed in this work have four terminals with top gate, bottom gate, source, and drain. The bottom gate is designed for solving disturbance issues.

Table 1 describes the film thickness and channel length for these devices. The simulated devices are composed of tunneling oxide layers with the same EOT of $3 \mathrm{~nm}$ for fair comparison. The blocking oxide is composed of $6 \mathrm{~nm} \mathrm{Al}_{2} \mathrm{O}_{3}$, and CTL is composed of $4 \mathrm{~nm} \mathrm{HfO} \mathrm{H}_{2}$. Bottom gate dielectric has a $3 \mathrm{~nm}$ thickness with $\mathrm{SiO}_{2}$. The length and thickness of the silicon channel are $40 \mathrm{~nm}$ and $12 \mathrm{~nm}$, respectively. A gate-drain underlap (gate-source overlap) structure is applied for suppressing ambipolar current [38,39], which undesirably increases the off-state current. In specific, since the ambipolar current occurs due to band-to-band-tunneling (BTBT) current in the body/drain region, it is possible to suppress the ambipolar current by locating the gate far from the drain, which is called gate-drain underlap $[38,39]$. 


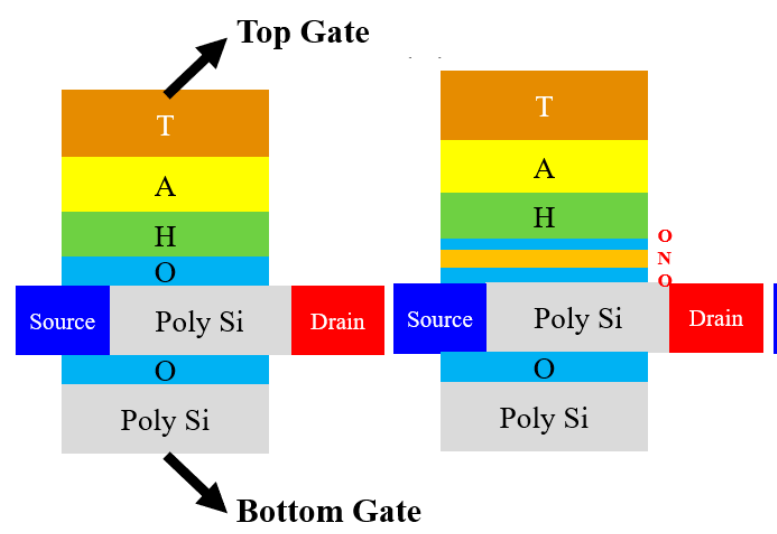

(a) (b)

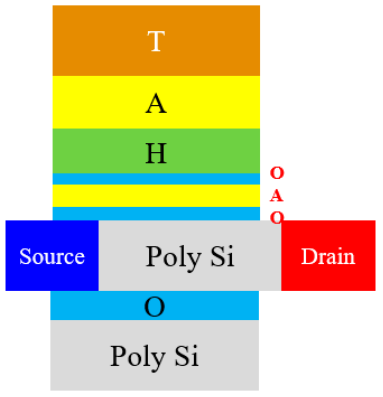

(c)

Figure 1. Schematic view illustrating (a) conventional $\mathrm{TaN} / \mathrm{Al}_{2} \mathrm{O}_{3} / \mathrm{HfO}_{2} / \mathrm{SiO}_{2} / \mathrm{Si}$ (TAHOS), (b) bandgap engineered (BE)-TAHOS, and (c) proposed TaN $/ \mathrm{Al}_{2} \mathrm{O}_{3} / \mathrm{HfO}_{2} / \mathrm{SiO}_{2} / \mathrm{Al}_{2} \mathrm{O}_{3} / \mathrm{SiO}_{2} / \mathrm{Si}$ (TAHOAOS) structure with two gate terminals. All structures commonly have $\mathrm{HfO}_{2}$ as chargetrapping layer (CTL) and $\mathrm{Al}_{2} \mathrm{O}_{3}$ as blocking oxide. The abbreviated letters $\mathrm{T}, \mathrm{A}, \mathrm{H}, \mathrm{O}, \mathrm{N}$ stand for tantalum nitride ( $\mathrm{TaN}$, gate metal), $\mathrm{Al}_{2} \mathrm{O}_{3}, \mathrm{HfO}_{2}, \mathrm{SiO}_{2}, \mathrm{Si}_{3} \mathrm{~N}_{4}$, respectively.

Table 1. Film thickness and channel length in conventional TAHOS, BE-TAHOS, and proposed TAHOAOS structure.

\begin{tabular}{ccc}
\hline Region & Material & Thickness (nm) \\
\hline & $\mathrm{SiO}_{2}$ & 3 \\
Tunneling oxide & $\mathrm{SiO}_{2} / \mathrm{Si}_{3} \mathrm{~N}_{4} / \mathrm{SiO}_{2}$ & $1 / 1.7 / 1$ \\
& $\mathrm{SiO}_{2} / \mathrm{Al}_{2} \mathrm{O}_{3} / \mathrm{SiO}_{2}$ & $1 / 2.3 / 1$ \\
Blocking oxide & $\mathrm{Al}_{2} \mathrm{O}_{3}$ & 6 \\
Charge-trapping layer & $\mathrm{HfO}_{2}$ & 4 \\
Bottom gate dielectric & $\mathrm{SiO}_{2}$ & 3 \\
Channel (length) & $\mathrm{Si}$ & 40 \\
Channel (thickness) & $\mathrm{Si}$ & 12 \\
\hline
\end{tabular}

\subsection{Model Physics and Model Parameters}

To carefully investigate the electrical characteristics in these three different structures, tunneling models such as band-to-band-tunneling (BTBT), Fowler-Nordheim (FN) tunneling, direct tunneling, and trap-assisted tunneling (TAT) are applied in this device simulation with Synopsys Sentaurus ${ }^{\mathrm{TM}}$ through a technology computer-aided design (TCAD) tool. Physical models including Shockley-Read-Hall (SRH) recombination and E-field saturation models are also applied for precisely analyzing the memory operation.

For details, we adopted various mobility models including the PhuMob mobility model, Enormal (Lombardi) mobility model, and thin-layer mobility model to consider interfacial surface calibration roughness scattering and Coulomb scattering. In addition, models of eHighFieldSaturation, hHighFieldSaturation, and Avalanche (CarrierTempDrive) are used for reflecting velocity saturation and avalanche breakdown. Non-local mesh, eBarrierTunneling, and hBarrierTunneling are utilized for applying FN tunneling and direct tunneling.

In modeling $\mathrm{HfO}_{2}$ as CTL, charge trap density of $1.2 \times 10^{20} \mathrm{~cm}^{-3}$ is applied for $\mathrm{HfO}_{2}$ ， which corresponds to its charge trap density in memory device [9-11]. Specifically, the energy depth of electron is set as $0.7 \mathrm{eV}$ from the lowest conduction band (LCB) of $\mathrm{HfO}_{2}$ [20], whereas the energy depth of hole is set as $2.9 \mathrm{eV}$ from the highest valence band (HVB) [21] of $\mathrm{HfO}_{2}$. On the other hand, in modeling $\mathrm{Al}_{2} \mathrm{O}_{3}$, charge trap density of $2.0 \times 10^{12} \mathrm{~cm}^{-3}$ is applied, and the energy depth of electron/hole is set as $0.4 / 2.7 \mathrm{eV}$ from LCB/HVB, respectively [8]. In addition, effective electron tunneling masses $\left(m_{\text {eff }}\right)$ of $0.55 \mathrm{~m}_{\mathrm{O}}, 0.2 \mathrm{~m}_{\mathrm{O}}$, and $0.4 \mathrm{~m}_{\mathrm{O}}$ are used in thin film of $\mathrm{SiO}_{2}$ [12], $\mathrm{HfO}_{2}$ [12], and $\mathrm{Al}_{2} \mathrm{O}_{3}$ [17], respectively. 


\subsection{Workflow of Study and Calibration Process}

Figure 2a illustrates the overall workflow of this paper. The calibration of memory device is performed with the fabricated memory devices [45,46], and then gate dielectric layers of $\mathrm{SiO}_{2} / \mathrm{Al}_{2} \mathrm{O}_{3} / \mathrm{SiO}_{2}$ is incorporated. Thereafter, validation of the proposed memory device structure is conducted in terms of retention characteristics and inhibition in the NOR flash array.

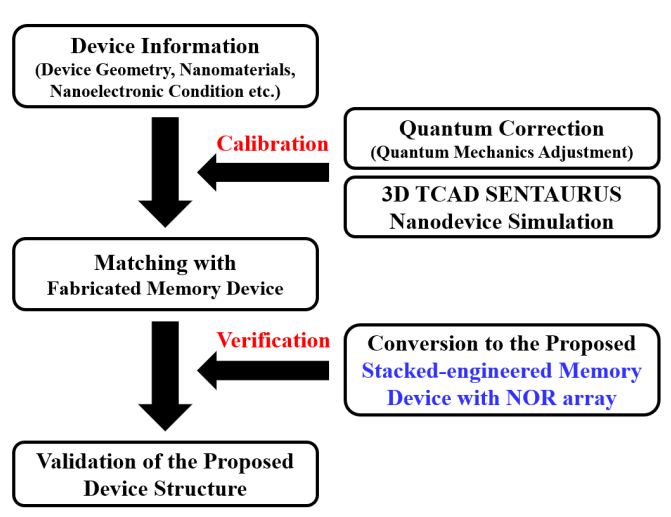

(a)

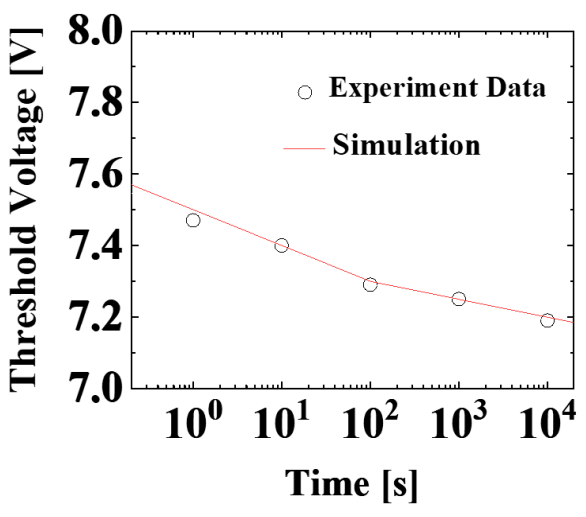

(b)

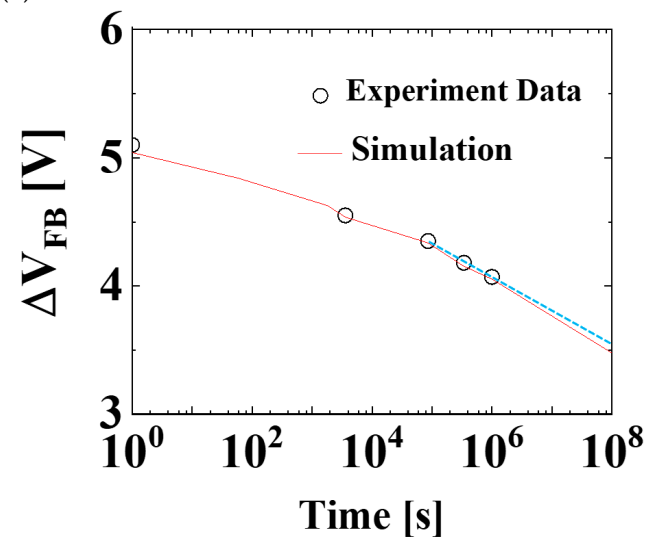

(c)

Figure 2. (a) Illustration that summarizes overall workflow of this paper; (b) calibration results based on the fabricated TANOS device [45]; (c) another calibration result based on fabricated BE-TAHOS device [46]. (Sky blue dot line indicates the linear approximation of retention characteristic in the fabricated BE-TAHOS device.).

During the calibration process, quantum correlations are carefully conducted for $I_{\mathrm{DS}}-I_{\mathrm{GS}}$ calibration, and retention calibration is performed under Synopsys Sentaurus ${ }^{\mathrm{TM}}$ three-dimensional (3D) TCAD simulation [47]. For details, we adopted various mobility models including the PhuMob mobility model, Enormal (Lombardi) mobility model, and thin-layer mobility model to consider interfacial surface calibration roughness scattering and Coulomb scattering. Firstly, $I_{\mathrm{DS}}-I_{\mathrm{GS}}$ calibration is performed by carefully adopting the velocity saturation model, quantum model, and gate work function (WF). Secondly, retention characteristics are carefully calibrated with the fabricated memory devices. Figure $2 b, c$ show our simulation results are well fit with the measured data of retention characteristics in the fabricated TaN $/ \mathrm{Al}_{2} \mathrm{O}_{3} / \mathrm{Si}_{3} \mathrm{~N}_{4} / \mathrm{SiO}_{2} / \mathrm{Si}$ (TANOS) device and BE-TAHOS device.

\section{Results and Discussion}

\subsection{Demonstration of NOR Flash Array with the Proposed Memory Device Structure}

Before demonstrating the retention enhancement from the proposed structure, the structure of the proposed memory device must be analyzed. In our proposed device structure, there are two major technological changes. 
First, the tunneling oxide layer is technically changed for increasing physical thickness and maintaining the same EOT of $3 \mathrm{~nm}$ at the same time (the exact thicknesses are shown in Table 1). Since the EOT of the three structures is the same, the initial transfer characteristics are almost the same, as shown in Figure 3.

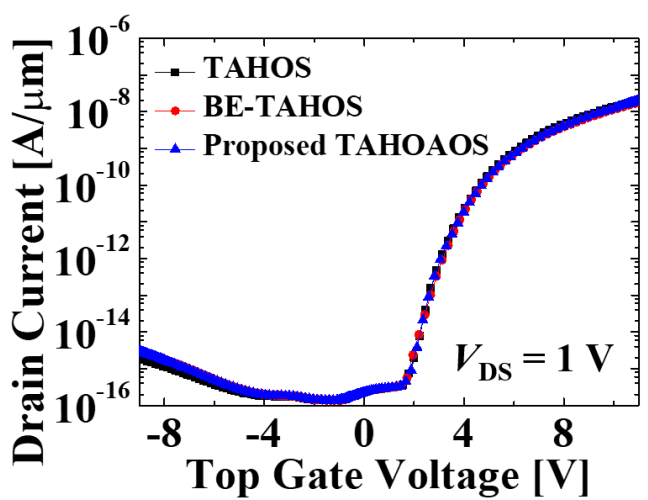

Figure 3. Basic transfer characteristics of three different device structures. These transfer characteristics show that our simulation is well designed with the same EOT thickness.

Second, the bottom gate was added to suppress programming of the unselected cell and solve disturbance issues [37]. Specifically, as illustrated in Figure 4, the additional bottom gates are connected with each other by the bottom gate line, which is perpendicular to the source line and word line. From this perpendicular design between the bottom gate line and word line, it is possible to program the selected cell only and inhibit programming of unselected cells, as described in the following paragraph.

NOR array design

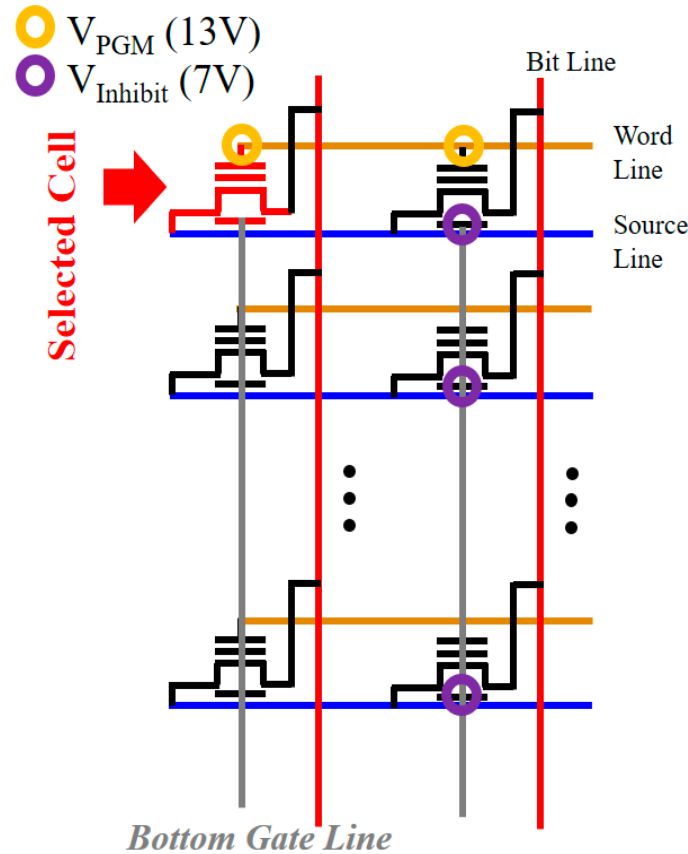

Figure 4. NOR array design for the proposed memory device structure. The newly added bottom gate line is perpendicular to the word line for selective programming.

For programming, the FN tunneling mechanism is used instead of the hot-carrier injection (HCI) mechanism, which has been widely adopted for the conventional programming method in the NOR flash array [48-50]. This is because the conventional HCI programming consumes significant power due to a significant drain current during programming [48]. On 
the other hand, FN programming can lower power consumption [37] due to its lower gate current compared to the higher drain current during HCI programming [48]. Therefore, FN tunneling is adopted for programming with low power consumption.

Table 2 describes the voltage applied in the selected cell and unselected cells during programming operation under the proposed NOR array design. Programming voltage $\left(V_{\text {PGM }}\right)$ of $13 \mathrm{~V}$ and inhibition voltage of $7 \mathrm{~V}$ are adopted, as only $13 \mathrm{~V}$ can program the memory cell in high- $k$-based memory devices (namely, TAHOS structure) due to low EOT of dielectric layers [18-21].

Table 2. The voltage applied in the selected cell and unselected cells during programming with the proposed NOR array design.

\begin{tabular}{ccc}
\hline Cell Type & Top Gate Voltage (V) & Bottom Gate Voltage (V) \\
\hline Selected cell & 13 & 0 \\
Unselected cell 1 & 13 & 7 \\
Unselected cell 2 & 0 & 7 \\
Unselected cell 3 & 0 & 0 \\
\hline
\end{tabular}

The different voltages are applied to the top gate and bottom gate of each cell, which serves as selective programming without disturbance issues. Consequently, as demonstrated in Figure 5, only the selected cell is programmed by FN tunneling, whereas the unselected cells are not. Regarding threshold voltage (Figure 5b), all three unselected cells show nearly zero threshold voltage shift just after programming, whereas the selected sell shows significant threshold voltage shift just after programming. This is because more than $10^{16} \mathrm{~cm}^{-3}$ trapped electron charge is needed for threshold voltage shift (Figure 5a,b) [18-21]. Therefore, it is possible to utilize our proposed structure in the NOR flash array without disturbance issues and increase the capacity of memory storage.

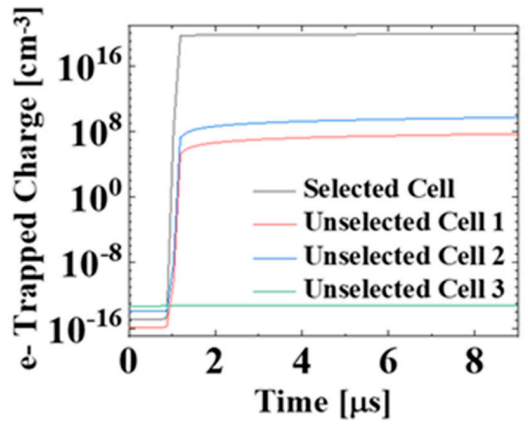

(a)

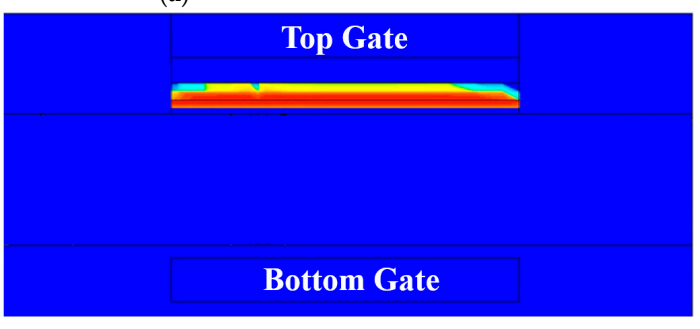

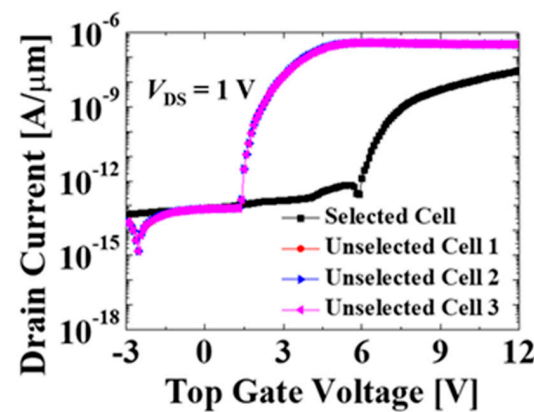

(b)

(c)

Trapped e- charge $\left[\mathrm{cm}^{-3}\right]$

Figure 5. (a) Change of electron charge trap density during programming at the cells of the proposed NOR array design. The density of trapped electron charge becomes saturated due to limited top gate voltage. In the selected cell, the higher top gate voltage may increase the saturated density of the trapped electron charge; (b) transfer characteristics just after programming of the cells in the proposed NOR array design; (c) cross-sectional view of the selected cell with TAHOS structure that illustrates the distribution of the trapped electron charge after programming. 


\subsection{Retention Enhancement of the Proposed Memory Device Structure}

In order to investigate the retention enhancement of the proposed TAHOAOS structure, devices with conventional TAHOS, and BE-TAHOS, proposed TAHOAOS structures are programmed and erased with top gate voltage as described in Figure 6a. Specifically, the high top gate voltage (17 V for programming and $-21 \mathrm{~V}$ for erasing) is applied in order to perform a fair comparison by matching initial threshold voltage (namely, threshold voltage when time is $10^{-3} \mathrm{~s}$ ). Then, retention characteristics of each structure are analyzed for 10 years. It is shown that our proposed TAHOAOS structure maintains a significant threshold voltage window for 10 years and is very strategic for retention characteristics, as demonstrated in Figure $6 \mathrm{~b}$.

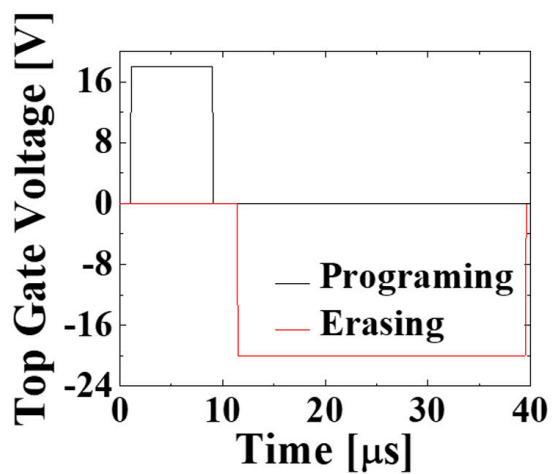

(a)

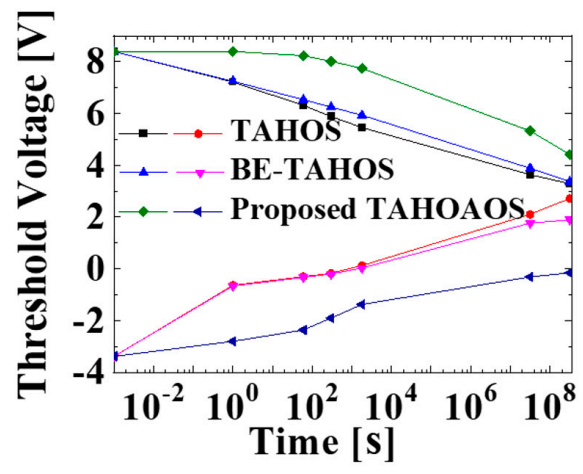

(b)

Figure 6. (a) Top gate bias during programming and erasing, and (b) retention characteristics of the conventional TAHOS, BE-TAHOS, and the proposed TAHOAOS structure. The high top gate voltage ( $17 \mathrm{~V}$ for programming and $-21 \mathrm{~V}$ for erasing) is applied in order to perform fair comparison by matching initial threshold voltage at 1 micro-second. (Specifically, programming with top gate voltage of $13 \mathrm{~V}$, as in Table 2, results in different initial threshold voltage [37], and hence programming with a higher top gate voltage of $17 \mathrm{~V}$ is performed for fair comparison.).

Specifically, our proposed TAHOAOS structure maintains $4.57 \mathrm{~V}$ of the threshold voltage window, whereas conventional TAHOS structure only maintains $0.57 \mathrm{~V}$ after 10 years from programming and erasing $(\mathrm{P} / \mathrm{E})$ as illustrated in Figure 7 . It is remarkable that our proposed TAHOAOS structure shows better retention characteristics (more than three times) compared to the BE-TAHOS structure.

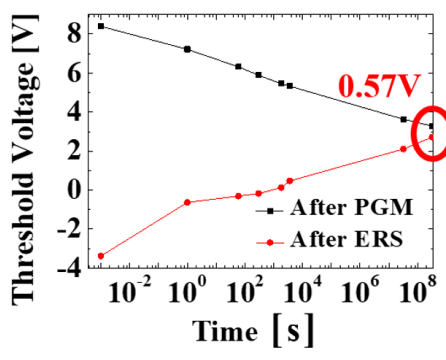

(a)

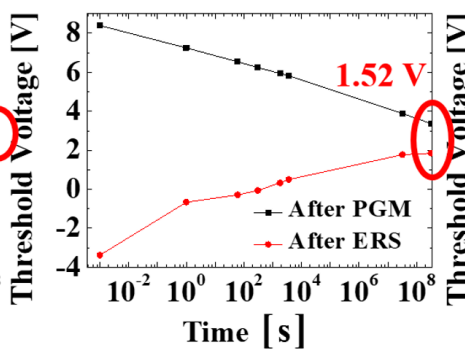

(b)

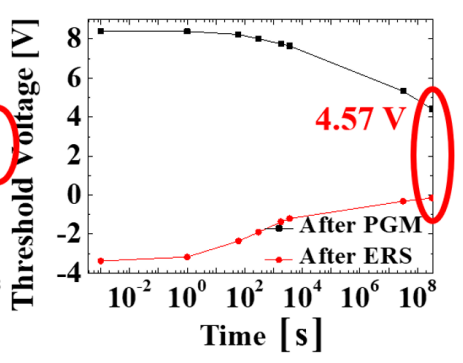

(c)

Figure 7. Detailed description of retention characteristics in (a) conventional TAHOS, (b) BE-TAHOS, and (c) proposed TAHOAOS structure.

However, there is one remarkable point in these retention characteristics. As shown in Figure $6 b$, the retention characteristics of conventional TAHOS and BE-TAHOS after erase operation (namely, red and pink line in Figure 6b) show barely little difference. Namely, even though retention characteristics of BE-TAHOS (pink line) is slightly better than that 
of conventional TAHOS (red line), the difference between them is reduced due to valence band offset.

This can be explained by energy band diagram. Figure 8 shows the energy band diagram of BE-TAHOS and the proposed TAHOAOS structure with reference to previous fabricated devices of the TAHOS and TANOS structure [51]. As illustrated in Figure 8a, substantial valence band offset exists in the BE-TAHOS structure. This valence band offset helps the hole to be ejected from $\mathrm{HfO}_{2} \mathrm{CTL}$. Therefore, the advantage of thicker tunneling oxide layers in BE-TAHOS (compared to conventional TAHOS) is reduced in terms of retention characteristics.

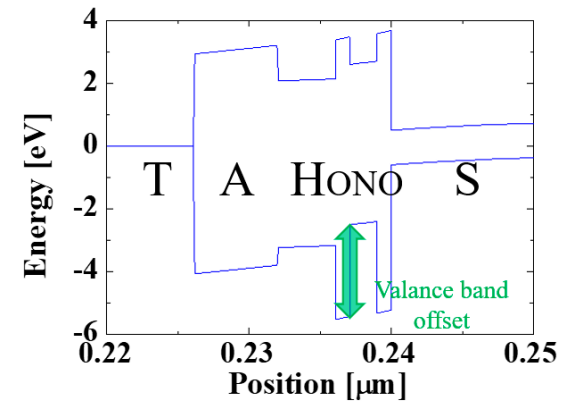

(a)

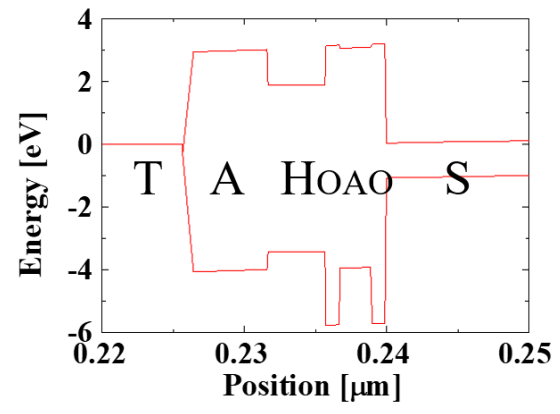

(b)

Figure 8. Energy band diagram of (a) BE-TAHOS, and (b) proposed TAHOAOS structure. Regarding retention characteristics, the valence band offset of BE-TAHOS (green arrow in panel a) mitigates the advantage of thicker tunneling oxide layers in BE-TAHOS. The abbreviated letters T, A, H, O, N stand for tantalum nitride (TaN, gate metal), $\mathrm{Al}_{2} \mathrm{O}_{3}, \mathrm{HfO}_{2}, \mathrm{SiO}_{2}, \mathrm{Si}_{3} \mathrm{~N}_{4}$, respectively.

On the other hand, the proposed TAHOAOS structure has not only thicker tunneling oxide layers but also lower valance band offset compared to BE-TAHOS (Figure 8). Therefore, regarding hole retention, the proposed TAHOAOS structure has a remarkable competitive edge, as demonstrated in Figure $6 \mathrm{~b}$.

Figure 9 shows the transfer curves after 10 years of $\mathrm{P} / \mathrm{E}$ operation in the conventional TAHOS structure and the proposed TAHOAOS structure. It is expected that our proposed structure can serve as a powerful tool for future big data markets with better reliability (retention), higher memory capacity, and low power operation (TFET-based memory [34-40]).
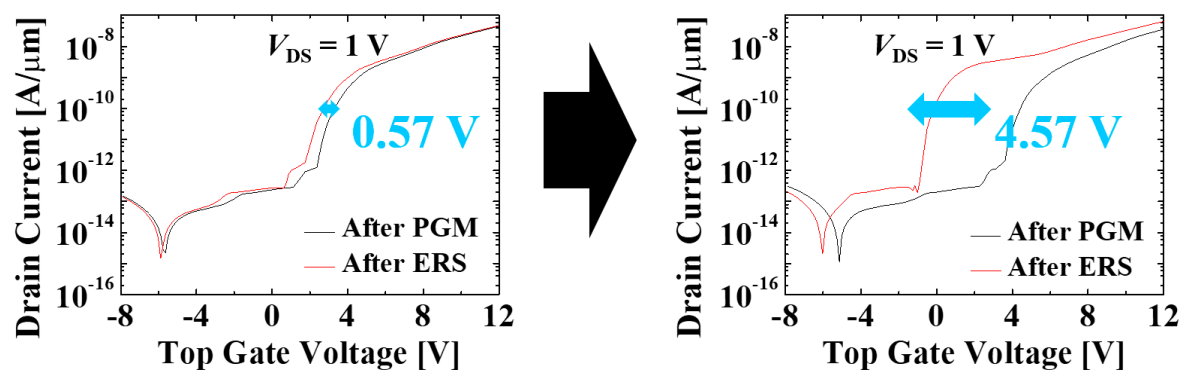

Figure 9. Enhancement of retention characteristics by the proposed tunneling oxide engineering. The graphs are calculated after 10 years of programming and erasing.

In summary, we have improved the retention characteristics with which $\mathrm{HfO}_{2}$-based nonvolatile charge-trapping memory has encountered [22-25], and opened up the possibility of practical application of $\mathrm{HfO}_{2}$-based NOR flash memory for better memory capacity.

\subsection{Proposal for Future Research}

We have proposed the design methodology for better retention characteristics and great immunity against disturbance issues by developing the TAHOAOS structure [37] 
on the NOR flash array. The proposed design technology is expected to improve the retention characteristics and decrease power consumption during programming (due to the programming method of FN tunneling) and during read operation (due to the TFETbased structure). Furthermore, it is expected that our newly proposed device structure with four terminals can solve the disturbance issue and make only a selected cell programmed.

However, even though our research has made considerable efforts to verify our proposed methodology, our research is basically limited to NOR flash application. We believe our proposed TAHOAOS structure can be applied beyond NOR flash application and to other fields such as 3D NAND flash and 3D AND flash. This is because our proposed technology may be applied in another domain by changing the design of the circuit. Therefore, we would like to suggest the future research topic to readers by analyzing our proposed technique in another array and another circuit design. It may be a desirable and interesting topic to develop our research with various future memory applications.

\section{Conclusions}

In this study, we propose the advanced structure for the NOR flash array with retention improvement. From the bottom gate effect, the disturbance issues are well suppressed, and it is possible to utilize the proposed structure in a NOR flash array. In addition, the threshold voltage window after 10 years of programming and erasing was considerably increased from $0.57 \mathrm{~V}$ to $4.57 \mathrm{~V}$ by incorporating $\mathrm{Al}_{2} \mathrm{O}_{3}$ in tunneling oxide layers. This enhancement is achieved by 1) high physical thickness of tunneling layers in the proposed structure (namely, high permittivity of $\mathrm{Al}_{2} \mathrm{O}_{3}$ ) and 2) lower valence band offset/conduction band offset in the proposed structure (namely, higher bandgap of $\mathrm{Al}_{2} \mathrm{O}_{3}$ compared to $\mathrm{Si}_{3} \mathrm{~N}_{4}$ ). These results open up the possibility of using enriched CTL $\left(\mathrm{HfO}_{2}\right)$ with improved retention characteristics. Therefore, the proposed TAHOAOS structure is very strategic for future highly integrated memory cells in big data markets with significant reliability enhancement.

Author Contributions: Writing-Original Draft \& Data curation, Y.S.S.; Writing-Review \& Editing, B.-G.P.; Validation, Y.S.S.; Supervision B.-G.P. All authors have read and agreed to the published version of the manuscript.

Funding: This work was supported by 2021 research fund of Korea Military Academy (Hwarangdae Research Institute).

Conflicts of Interest: The authors declare no conflict of interest.

\section{References}

1. Imran, A.; Zoha, A.; Abu-Dayya, A. Challenges in 5G: How to empower SON with big data for enabling 5G. IEEE Netw. 2014, 28, 27-33. [CrossRef]

2. Zheng, K.; Yang, Z.; Zhang, K.; Chatzimisios, P.; Yang, K.; Xiang, W. Big data-driven optimization for mobile networks toward 5G. IEEE Netw. 2016, 30, 44-51. [CrossRef]

3. Han, Q.; Liang, S.; Zhang, H. Mobile cloud sensing, big data, and 5G networks make an intelligent and smart world. IEEE Netw. 2015, 29, 40-45. [CrossRef]

4. Zhang, H.; Chen, G.; Ooi, B.C.; Tan, K.; Zhang, M. In-Memory Big Data Management and Processing: A Survey. IEEE Trans. Knowl. Data Eng. 2015, 27, 1920-1948. [CrossRef]

5. Wang, Y.; Yu, H. An ultralow-power memory-based big-data computing platform by nonvolatile domain-wall nanowire devices. In Proceedings of the International Symposium on Low Power Electronics and Design (ISLPED), Beijing, China, 4-6 September 2013.

6. Hamdioui, S.; Xie, L.; Anh Du Nguyen, H.; Taouil, M.; Bertles, K.; Corporaal, H.; Jiao, H.; Cathoor, F.; Wouters, D.; Eike, L.; et al. Memristor based computation-in-memory architecture for data-intensive applications. In Proceedings of the Design, Automation \& Test in Europe Conference \& Exhibition (DATE), Grenoble, France, 9-13 March 2015.

7. Yoon, S.-M.; Lee, N.-Y.; Ryu, S.-O.; Choi, K.-J.; Park, Y.-S.; Lee, S.-Y.; Yu, B.-G.; Kang, M.-J.; Choi, S.-J.; Wuttig, M. Sb-Se-based phase-change memory device with lower power and higher speed operations. IEEE Electron. Device Lett. 2006, $27,445-447$. [CrossRef]

8. Marcon, D.; Van Hove, M.; De Jaeger, B.; Posthuma, N.; Wellekens, D.; You, S.; Kang, X.; Wu, T.-L.; Willems, M.; Stoffels, S.; et al. Direct comparison of GaN-based e-mode architectures (recessed MISHEMT and p-GaN HEMTs) processed on $200 \mathrm{~mm}$ GaN-on-Si with Au-free technology. In Proceedings of the SPIE 9363, Gallium Nitride Materials and Devices X, San Francisco, CA, USA, 13 March 2015. 
9. Zhu, W.J.; Ma, T.P.; Zafar, S.; Tamagawa, T. Charge trapping in ultrathin hafnium oxide. IEEE Electron. Device Lett. 2002, 23, 597-599. [CrossRef]

10. Zou, X.; Jin, L.; Yan, L.; Zhang, Y.; Ai, D.; Zhao, C.; Xu, F.; Li, C.; Huo, Z. The influence of grain boundary interface traps on electrical characteristics of top select gate transistor in 3D NAND flash memory. Solid State Electron. 2019, 153, 67-73. [CrossRef]

11. Yao, Y.; Li, C.; Huo, Z.L.; Liu, M.; Zhu, C.X.; Gu, C.Z.; Duan, X.F.; Wang, Y.G.; Gu, L.; Yu, R.C. In situ electron holography study of charge distribution in high-k charge-trapping memory. Nat. Commun. 2013, 4, 1-8. [CrossRef]

12. Hinkle, C.L.; Fulton, C.; Nemanich, R.J.; Lucovsky, G. A novel approach for determining the effective tunneling mass of electrons in $\mathrm{HfO} 2$ and other high-K alternative gate dielectrics for advanced CMOS devices. Microelectron. Eng. 2004, 72, $257-262$. [CrossRef]

13. Ali, T.; Polakowski, P.; Riedel, S.; Büttner, T.; Kämpfe, T.; Rudolph, M.; Pätzold, B.; Seidel, K.; Löhr, D.; Hoffmann, R.; et al. High Endurance Ferroelectric Hafnium Oxide-Based FeFET Memory Without Retention Penalty. IEEE Trans. Electron. Devices 2018, 65, 3769-3774. [CrossRef]

14. Lee, B.H.; Kang, L.; Qi, W.J.; Nieh, R.; Jeon, Y.; Onishi, K.; Lee, J.C. Ultrathin hafnium oxide with low leakage and excellent reliability for alternative gate dielectric application. In Proceedings of the International Electron Devices Meeting (IEDM), Washington, DC, USA, 5-8 December 1999.

15. Choi, Y.; Lee, K.; Kim, K.Y.; Kim, S.; Lee, J.; Lee, R.; Kim, H.-M.; Song, Y.S.; Kim, S.; Lee, J.-H.; et al. Simulation of the effect of parasitic channel height on characteristics of stacked gate-all-around nanosheet FET. Solid State Electron. 2020, 164, 107686. [CrossRef]

16. Kim, J.H.; Kim, H.W.; Song, Y.S.; Kim, S.; Kim, G. Analysis of Current Variation with Work Function Variation in L-Shaped Tunnel-Field Effect Transistor. Micromachines 2020, 11, 780. [CrossRef] [PubMed]

17. Molina-Reyes, J.; Uribe-Vargas, H.; Torres-Torres, R.; Mani-Gonzalez, P.G.; Herrera-Gomez, A. Accurate modeling of gate tunneling currents in Metal-Insulator-Semiconductor capacitors based on ultra-thin atomic-layer deposited $\mathrm{Al}_{2} \mathrm{O}_{3}$ and postmetallization annealing. Thin Solid Film. 2017, 638, 48-56. [CrossRef]

18. Xu, W.C.; He, H.X.; Jing, X.S.; Wu, S.J.; Zhang, Z.; Gao, J.W.; Gao, X.S.; Zhou, G.F.; Lu, X.B.; Liu, J.-M. High performance organic nonvolatile memory transistors based on $\mathrm{HfO}_{2}$ and poly ( $\alpha$-methylstyrene) electret hybrid charge-trapping layers. Appl. Phys. Lett. 2017, 111, 1-5. [CrossRef]

19. You, H.-C.; Kuo, P.-Y.; Ko, F.-H.; Chao, T.-S.; Lei, T.-F. The Impact of Deep Ni Salicidation and hbox $\mathrm{NH}_{3}$ Plasma Treatment on Nano-SOI FinFETs. IEEE Electron. Device Lett. 2006, 27, 799-801. [CrossRef]

20. Driussi, F.; Spiga, S.; Lamperti, A.; Congedo, G.; Gambi, A. Simulation Study of the Trapping Properties of $\mathrm{HfO}_{2}$-Based Charge-Trap Memory Cells. IEEE Trans. Electron. Devices 2014, 61, 2056-2063. [CrossRef]

21. Zhang, Y.; Shao, Y.Y.; Lu, X.B.; Zeng, M.; Zhang, Z.; Gao, X.S.; Zhang, X.J.; Liu, J.-M.; Dai, J.Y. Defect states and charge trapping characteristics of $\mathrm{HfO}_{2}$ films for high performance nonvolatile memory applications. Appl. Phys. Lett. 2014, 105, 172902. [CrossRef]

22. Stesmans, A.; Afanasev, V.V. Defect correlated with positive charge trapping in functional $\mathrm{HfO}_{2}$ layers on (100)Si revealed by electron spin resonance: Evidence for oxygen vacancy? Microelectron. Eng. 2017, 178, 112-115. [CrossRef]

23. Chen, Y.Y.; Goux, L.; Clima, S.; Govoreanu, B.; Degraeve, R.; Sankar Kar, G.; Fantini, A.; Groesenken, G.; Wouters, D.J.; Jurczak, M.; et al. Endurance/Retention Trade-off on HfO2/Metal Cap 1T1R Bipolar RRAM. IEEE Trans. Electron. Devices 2013, 60, 1114-1121. [CrossRef]

24. Mitrovic, I.Z.; Luy, Y.; Buiu, O.; Hall, S. Current transport mechanisms in $\mathrm{HfO}_{2} \mathrm{xSiO} 21-\mathrm{x} / \mathrm{SiO}_{2}$ gate stacks. Microelectron. Eng. 2007, 84, 2306-2309. [CrossRef]

25. Cerbu, F.; Madia, O.; Andreev, D.V.; Fadida, S.; Eizenberg, M.; Breuil, L.; Lisoni, J.G.; Kittl, J.A.; Strand, J.; Shluger, A.L.; et al. Intrinsic electron traps in atomic-layer deposited HfO2 insulators. Appl. Phys. Lett. 2016, 108, 1-5. [CrossRef]

26. Bersuker, G.; Sim, J.H.; Park, C.S.; Young, C.D.; Nadkarni, S.V.; Choi, R.; Lee, H.B. Mechanism of Electron Trapping and Characteristics of Traps in HfO2 Gate Stacks. IEEE Trans. Device Mater. Reliab. 2007, 7, 138-145. [CrossRef]

27. Khosla, R.; Rolseth, E.G.; Kumar, P.; Vadakupudhupalayam, S.S.; Sharma, S.K.; Schulze, J. Charge Trapping Analysis of Metal/Al2O3/SiO2/Si, Gate Stack for Emerging Embedded Memories. IEEE Trans. Device Mater. Reliab. 2017, 17, 80-89. [CrossRef]

28. Xu, Z.; Huo, Z.; Zhu, C.; Cui, Y.; Wang, M.; Zheng, Z.; Liu, J.; Wang, Y.; Li, F.; Liu, M. Performance-improved nonvolatile memory with aluminum nanocrystals embedded in Al2O3 for high temperature applications. J. Appl. Phys. 2011, 110, 1-5. [CrossRef]

29. Gu, S.-H.; Hsu, C.-W.; Wang, T.; Lu, W.-P.; Ku, Y.-H.J.; Lu, C.-Y. Numerical Simulation of Bottom Oxide Thickness Effect on Charge Retention in SONOS Flash Memory Cells. IEEE Trans. Electron. Devices 2006, 54, 90-97. [CrossRef]

30. King, Y.-C.; Liu, T.-J.K.; Hu, C. A long-refresh dynamic/quasi-nonvolatile memory device with 2-nm tunneling oxide. IEEE Electron. Device Lett. 1999, 20, 409-411. [CrossRef]

31. Hanafi, H.; Tiwari, S.; Khan, I. Fast and long retention-time nano-crystal memory. IEEE Trans. Electron. Devices 1996, 43, 1553-1558. [CrossRef]

32. Malavena, G.; Spinelli, A.S.; Compagnoni, C.M. Implementing Spike-Timing-Dependent Plasticity and Unsupervised Learning in a Mainstream NOR Flash Memory Array. In Proceedings of the 2018 IEEE International Electron Devices Meeting (IEDM), San Francisco, CA, USA, 1-5 December 2018; pp. 1-4. 
33. Malavena, G.; Filippi, M.; Spinelli, A.S.; Compagnoni, C.M. Unsupervised Learning by Spike-Timing-Dependent Plasticity in a Mainstream NOR Flash Memory Array-Part I: Cell Operation. IEEE Trans. Electron. Devices 2019, 66, 4727-4732. [CrossRef]

34. Lue, H.-T.; Wang, S.Z.; Lai, E.-K.; Shih, Y.-H.; Lai, S.-C.; Yang, L.-W.; Chen, K.-C.; Ku, J.; Hsieh, K.-Y.; Liu, R.; et al. BE-SONOS: A bandgap engineered SONOS with excellent performance and reliability. In Proceedings of the IEEE International Electron Devices Meeting, Washington, DC, USA, 5 December 2005.

35. Lue, H.-T.; Wang, S.-Y.; Lai, E.-K.; Hsieh, K.-Y.; Liu, R.; Lu, C.Y. A BE-SONOS (Bandgap Engineered SONOS) NAND for Post-Floating Gate Era Flash Memory. In Proceedings of the 2007 International Symposium on VLSI Technology, Systems and Applications (VLSI-TSA), Hsinchu, Taiwan, 23-25 April 2007; pp. 1-2.

36. Hsu, T.-H.; Lue, H.T.; King, Y.-C.; Hsieh, J.-Y.; Lai, E.-K.; Hsieh, K.-Y.; Liu, R.; Lu, C.-Y. A High-Performance Body-Tied FinFET Bandgap Engineered SONOS (BE-SONOS) for nand-Type Flash Memory. IEEE Electron. Device Lett. 2007, 28, 443-445. [CrossRef]

37. Song, Y.S.; Jang, T.; Min, K.K.; Baek, M.-H.; Yu, J.; Kim, Y.; Lee, J.-H.; Park, B.-G. Tunneling oxide engineering for improving retention in nonvolatile charge-trapping memory with TaN $/ \mathrm{Al}_{2} \mathrm{O}_{3} / \mathrm{HfO}_{2} / \mathrm{SiO}_{2} / \mathrm{Al}_{2} \mathrm{O}_{3} / \mathrm{SiO}_{2} / \mathrm{Si}$ structure. Jpn. J. Appl. Phys. 2020, 59, 61006. [CrossRef]

38. Khatami, Y.; Banerjee, K. Steep Subthreshold Slope n- and p-Type Tunnel-FET Devices for Low-Power and Energy-Efficient Digital Circuits. IEEE Trans. Electron. Devices 2009, 56, 2752-2761. [CrossRef]

39. Yu, J.; Kim, S.; Baek, M.-H.; Min, K.K.; Jang, T.; Song, Y.S.; Park, B.G. Investigation of Ambipolar Current Suppression Using Dual Work Function Metal Gate in L-Shaped Tunnel Field Effect Transistor. In Proceedings of the IEIE Summer Conference, Jeju-do, Korea, 26-28 June 2019.

40. Kim, Y.; Kim, T.; Beak, M.H.; Jang, T.; Song, Y.S.; Jeon, B.; Park, B.G. An Area Efficient Adaptive Neuron Circuit Exploiting Tunnel Field-Effect Transistor. In Proceedings of the IEIE Summer Conference, Jeju-do, Korea, 26-28 June 2019.

41. Tripathy, M.R.; Singh, A.K.; Samad, A.; Chander, S.; Baral, K.; Singh, P.K.; Jit, S. Device and Circuit-Level Assessment of GaSb/Si Heterojunction Vertical Tunnel-FET for Low-Power Applications. IEEE Trans. Electron. Devices 2020, 67, 1285-1292. [CrossRef]

42. Kim, T.; Park, K.; Jang, T.; Baek, M.-H.; Song, Y.S.; Park, B.-G. Input-modulating adaptive neuron circuit employing asymmetric floating-gate MOSFET with two independent control gates. Solid State Electron. 2020, 163, 107667. [CrossRef]

43. Kim, T.; Song, Y.S.; Park, B.-G. Overflow Handling Integrate-and-Fire Silicon-on-Insulator Neuron Circuit Incorporating a Schmitt Trigger Implemented by Back-Gate Effect. J. Nanosci. Nanotechnol. 2019, 19, 6183-6186. [CrossRef]

44. Song, Y.S.; Kim, J.H.; Kim, G.; Kim, H.-M.; Kim, S.; Park, B.-G. Improvement in Self-Heating Characteristic by Incorporating Hetero-Gate-Dielectric in Gate-All-Around MOSFETs. IEEE J. Electron. Devices Soc. 2021, 9, 36-41. [CrossRef]

45. Park, H.; Bersuker, G.; Gilmer, D.; Lim, K.Y.; Jo, M.; Hwang, H.; Padovani, A.; Larcher, L.; Pavan, P.; Taylor, W.; et al. Charge loss in TANOS devices caused by Vt sensing measurements during retention. In Proceedings of the 2010 IEEE International Memory Workshop, Seoul, Korea, 16-19 May 2010; pp. 1-2. [CrossRef]

46. Congedo, G.; Lamperti, A.; Salicio, O.; Spiga, S. Multi-Layered $\mathrm{Al}_{2} \mathrm{O}_{3} / \mathrm{HfO}_{2} / \mathrm{SiO}_{2} / \mathrm{Si}_{3} \mathrm{~N}_{4} / \mathrm{SiO}_{2}$ Thin Dielectrics for Charge Trap Memory Applications. ECS J. Solid State Sci. Technol. 2013, 2, N1-N5. [CrossRef]

47. Synopsys Inc. Version K-2015.06-SP; Synopsys Inc.: Mountain View, CA, USA, 2017.

48. Della Marca, V.; Postel-Pellerin, J.; Just, G.; Canet, P.; Ogier, J.-L. Impact of endurance degradation on the programming efficiency and the energy consumption of NOR flash memories. Microelectron. Reliab. 2014, 54, 2262-2265. [CrossRef]

49. Compagnoni, C.M.; Chiavarone, L.; Calabrese, M.; Ghidotti, M.; Lacaita, A.L.; Spinelli, A.S.; Visconti, A. Fundamental Limitations to the Width of the Programmed VTVT Distribution of nor Flash Memories. IEEE Trans. Electron. Devices 2010, 57, 1761-1767. [CrossRef]

50. Choi, S.-J.; Han, J.-W.; Kim, S.; Moon, D.-I.; Jang, M.-G.; Kim, J.S.; Kim, K.H.; Lee, G.S.; Oh, J.S.; Song, M.H.; et al. Performance Breakthrough in NOR Flash Memory with Dopant-Segregated Schottky-Barrier (DSSB) SONOS Devices. In Proceedings of the 2009 Symposium on VLSI Technology, Kyoto, Japan, 15-17 June 2009.

51. Spiga, S.; Congedo, G.; Russo, U.; Lamperti, A.; Salicio, O.; Driussi, F.; Vianello, E. Experimental and simulation study of the program efficiency of $\mathrm{HfO} 2$ based charge trapping memories. In Proceedings of the 2010 European Solid State Device Research Conference, Sevila, Spain, 14-16 September 2010; pp. 408-411. 